\title{
Cyberethnography as home-work ${ }^{1}$
}

\author{
Adi Kuntsman (Lancaster University)
}

Cyberspace invites the rethinking of the concepts culture and location. But it also demands a re-examination of the idea of 'the field' in virtual — or what is also called cyber-ethnography. This article focuses on one way of locating the field in cyberspace by exploring the concept of home as it is conceptualized by the ethnographer and imagined and negotiated by those with whom she works. The article suggests a critical way of approaching belonging on-line, and examines the epistemological position of anthropology at home when applied to cyberspace. On a theoretical level, this article brings together the growing field of cyber-studies and critical feminist and post-colonial perspectives.

Cyberspace as a new field site demands rethinking concepts of culture and location. In the past decade it has become a site of growing interest for sociologists, anthropologists, linguists and other social scientists. More and more scholars attempt to conceptualize it in terms of space, location and geography-whether by suggesting that cyberspace is a placeless terrain of networks and flows or by looking at cyberspace as yet another locality with its own rules. But cyberspace also demands reexamining the very idea of 'the field' in virtual—or what is also called cyberethnography. How and where is this field located? Is the anthropology of cybercultures 'anthropology at home'?

This article focuses on one way of locating the field in cyberspace by exploring the concept of home as it is conceptualized by the ethnographer and by those with whom she works. My attempt here is to question the perception of cyberspace as a liberatory site of unlimited imagination and freedom. Instead I hope to suggest a critical way of examining belonging in cyberspace that takes into account both the opportunities and the constraints. What kind of home(s) does cyberspace allow, and for whom are these homes available? And last but not least, I will look at the epistemological position of anthropology at home when applied to cyberspace. On a theoretical level, this article brings together the growing field of cyber-studies and critical feminist and postcolonial perspectives.

\section{Fields and fieldworks in cyberspace}

From the traditional anthropological point of view, cyberspace appears to be 'at home' and 'away' at the same time. On the one hand, one doesn't need to leave home in order to do it (Hine 2000, Paccagnella 1997). What's more, most of today's studies

\footnotetext{
${ }^{1}$ I wish to express my thanks to Tom Rice, Paul Strauss and the anonymous reviewer of Anthropology Matters for their insightful comments on earlier versions of this paper. I am also grateful to Yehudit Keshet for her editing assistance and her overall support.
} 
of 'cybercultures' deal with the society of the researcher, which is almost always located on the Western side of the digital divide. The notion of the digital divide as a divide between 'the West and the rest' is, of course, a simplified one that seems to overlook complex relations of class, wealth, education and accessibility within Western as well as non-Western societies. Such complicated analysis, while crucial to understanding the internet, lies beyond the limits of this paper. It is important to mention, however, that it is the West that often appears to be a 'natural' place for cybercultures to develop, while always being a foreign innovation in non-Western countries. $^{2}$

At the same time, cyberspace itself is often exotisized as a distant and different space:

\begin{abstract}
'Just as the exploration of the American western frontier provided an opportunity for humanity to conquer new space, so does the exploration of cyberspace. We seek to pioneer new spaces, to create in them, to live in them. [...] It represents our humanity, our freedom.'
\end{abstract}

(Fernback 1999: 214)

Such discourses of humane conquest, dangerously similar to the European discourse of colonization as exploration and discovery, hide the fact that cyberspace is constituted through violence and exclusion as well as through opportunities and explorations; that it is not equally accessible to all, and that its population is privileged in terms of class and geographical location (Oguibe 1996). But what is even more interesting is the fact that such exoticizing of cyberspace evokes the traditional anthropological notion of travel.

The notion of travel and distance has traditionally constituted the anthropological idea of the 'field'. The field appeared in the disciplinary imagination as located 'out there' and inhabited by people whose culture is different from that of the researcher. In the past decades these epistemologies were challenged and deconstructed by feminist and post-colonial (or non-white or "third-world' ${ }^{3}$ or "halfie" ) anthropologists. They theorized their experience as the simultaneous 'selves' and 'others' of anthropology (Abu-Lughod 1991) and disrupted the distinction between 'here' (in the West) as the locus of knowledge and 'there' (outside of the West) as a series of fixed and exotic cultural locales (Lavie and Swedenburg 1996). Thus, these theorists have challenged the very dichotomy between the 'field' as the location of the 'culture' to be studied, and home as a place where the field notes of the anthropologist are read and analysed.

So what does it mean when research about cybercultures evokes, yet again, the traditional notions of travel, distance and discovery? How can fieldwork in cyberspace be understood and (re)defined? Where should it be located?

\footnotetext{
${ }^{2}$ See, for example, Miller and Slater's discussion of the internet in Trinidad. In the introduction to their book, The internet: an ethnographic approach (2000), the authors describe their surprise at how naturally Trinidadians experienced being on-line (the internet having come into their lives fairly recently). At the same time a number of internet studies open their introductions by reminding the reader that the internet originated as a US military project. Such genealogies locate cybercultures as naturally belonging to the West. What's more, internet cultures are often seen as a sign of westernness.

${ }^{3}$ The term used by Lavie and Swedenburg (1996).

${ }^{4}$ The term used by Abu-Lughod (1991).
} 
Most internet studies written and published in the past decade project a feeling of innovation in both the conceptual and the methodological understanding of fieldwork in cyberspace (Fernback 1999, Kendall 1999, Stone 2001). Many have suggested new definitions of the 'field' in cyberspace. For example, Annette Markham (2004) puts forward the concept of discursive, rather than geographical, boundaries of the field; Christine Hine (2000) describes the idea of 'virtual ethnography' that follows an event rather than a culture or a location; and Kate Eichhorn (2001) suggests using the term 'textual community' in relation to the ethnography of 'sites unseen' in order to contest the anthropological 'legacy of the field'. These and other studies propose, in different ways, that cyberspace enables (and even forces) us to re-examine and reframe old concepts of fieldwork.

While I share this feeling of theoretical potential that is embedded in cyberspace and find the above mentioned concepts interesting and useful, I am also struck by the fact that these debates often ignore the critical discussion of anthropological practices and epistemologies led by feminist and post-colonial anthropologists. ${ }^{5}$ One of the central contributions of these theorists was to identify a transition towards 'anthropology at home' as a move away from the power relations between anthropologists from 'here' who study 'primitive' and exotic subjects 'there'. Kamala Visweswaran took this idea further, suggesting that anthropology should become home-work and not simply 'anthropology at home' (Visweswaran 1997). While the latter, she states, has usually been conducted by white anthropologists among 'Others' in the West, home-work would dehegemonize the white Euro-center itself. In their reflections on this term, Lavie and Swedenburg further argue that

'In the process of decolonizing fieldwork and making it into homework,
home is destabilized and cannot remain "an illusion of coherence and
safety based on the exclusion of specific histories of oppression and
resistance, the repression of difference even within oneself"' (Martin and
Mohanty 1986:1996, quoted in Lavie and Swedenburg, 1996: 170-71).

The central idea of anthropology as home-work unfixes the very idea of 'home'. No longer an unproblematic location of 'belonging', home becomes a site of investigation and negotiation. It is this theoretical move towards a critical examination of home(s) that interests me here. I am particularly interested in the ways home can be imagined, defined and negotiated on-line, and how online homes participate in the very experience of fieldwork in cyberspace. Cyberspace provides new opportunities for deterritorialized home-making, especially for migrants and diasporic subjects (Gajjala 2002). It can bring together physically dispersed people, provide a space of communication for socially marginalized groups and serve as a resource for community organizing. Yet homes and fields in cyberspace should be examined critically. What subjects get a voice in these cyber-homes, and who is left home-less? What kind of power relations are reproduced and why? When and how can they be challenged?

The rest of this article will present some reflections on my current cyber-fieldwork-inprogress. I will look at the notions of home and home-making on the website of Russian speaking GLBT ${ }^{6}$ immigrants in Israel. In particular, I will reflect on the

\footnotetext{
${ }^{5}$ One notable exception is the work done by Radhika Gajjala (1996, 2002), another is an ongoing project conducted by Michaela Fay $(2002,2004)$. Both studies are discussed later in the paper.

${ }^{6}$ Gays, lesbians, bisexuals and transgender.
} 
different ways homes can be imagined, negotiated and challenged in cyberspace. I will then ask how those notions of home affect the experience and the definition of fieldwork in cyberspace.

\section{Homey cyberspaces and the national homeland}

My research on Russian-speaking GLBT immigrants in Israel began many years ago with my own immigration story of coming out. For me the moment of establishing my lesbian identity in the Israeli Hebrew-speaking GLBT community was also the moment of establishing my belonging in Israel which later was challenged by my political activism. Informed by queer theory and gay and lesbian studies on the one hand, and by research on nationhood and Israeli society on the other, I have long been interested in the relations between national and sexual belonging in Israel.

During my MA studies I began interviewing other immigrant women from Russia who, like me, became actively involved in the Hebrew-speaking lesbian community in the mid-1990s. Many of them told me about their experience of shedding their Russian skin, becoming 'Israeli lesbians', detaching from other immigrants and from their mother tongue. My and their narratives of immigration to Israel were that of 'double homecoming': leaving Russia was experienced as the transformation of sexuality and finding a home in the Hebrew-speaking queer community; this home also mediated the sense of re-grounding and belonging in Israel (Kuntsman 2003). While these homecoming stories are far from representative of all Russian queer migrants and describe a very particular age, gender and class experience, they also signify a particular moment in time before the appearance of the Russian queer collective presence in Israel.

My current research follows what I call queer Russianscapes that were established around 2000. One of the main such scapes is located online and creates a place for a feeling of shared cultural and/or sexual experience. The Russian GLBT collective presence emerged about a decade after the beginning of a big wave of immigration from the former Soviet Union. ${ }^{7}$ Around that time the first social group of Russian speaking queers was organized in Jerusalem, followed by a larger and more active one established in Tel-Aviv. At about the same time a group of friends decided to create a website. Their main aim at first was to provide information and announcements about Russian GLBT activities in Tel-Aviv. Later the site developed into a news teller. Started as a small project run by several enthusiasts, the site quickly became the main Russian-speaking source of information on GLBT issues in Israel.

But soon this website took on an unexpected dimension. A bulletin board, which was originally designed mainly as a dating service, soon grew into a large and vibrant discussion forum. Today the discussion forum is one of the main sites of Russian queer community life. While a 'home' for some (an idea I return to below), it is a welcoming place to visit for others or yet another source of information one can look through while cruising the net for other users.

When I first began participating in the discussion forum, I felt strange discussing queer issues in Russian, since for me at that time Russian and queer appeared as two

\footnotetext{
${ }^{7}$ Over one million immigrants from the FSU have arrived since 1989 (Central Bureau of Statistics of Israel 2002).
} 
opposite poles of a clear-cut dichotomy. For me and some other women who became active in the Israeli GLBT community in the mid-1990s, lesbian identity was constituted through detaching from Russianness; the language, the appearance, and the identification with other Russian-speaking immigrants.

In a way, the site became my way back to my Russian identity, or at least some parts of it. This identity was performed through the use of the Russian language, ${ }^{8}$ but also through repetitive presence at the site of Russian-speaking participants. My feeling of going back to what was earlier shed as a useless skin was echoed by one of the uses of the bulletin board who defined the website as her way of re-connecting to her roots.

However, her and my feelings do not necessarily reflect the experience of other women. For many of the participants Russian has always been, and remained, their main language. For others the site did not provide a space of belonging. For example, one woman who I interviewed for my previous study, and later met on one of my field trips to Israel, told me that she had not felt comfortable with the kind of queer Russian-Israeli identities that were constituted on the site. She had felt more and more estranged and had eventually left. I also found myself taken aback every now and then when I could not voice my political beliefs on the site, because they seemed to strongly contradict the dominant right-wing atmosphere (I will come back later to the role of the political debates on the site and the kinds of speech and silence they produce). Thus this cybercommunity has simultaneously become a home-coming field and a site of estrangement from my own community.

The website, then, serves as a site for the constitution and negotiation of RussianIsraeli identity by queer immigrants. While a more detailed discussion of ethnicity and belonging lies beyond the limits of this paper, it is important to point out that sexuality often plays a central role in one's feeling of home in this online community.

For me, it is an outlet, a source of air... A place to meet interesting people. And considering that my homosexual life is somewhat virtual It's one of the main places, where I can be myself... wrote one of the participants in the e-mail interview.

His words resonate with those of another one:

[For me] It's a place, where I can speak openly about my love for a woman, without being misunderstood.

These and many other participants relate to the website as a welcoming place of what Anne-Marie Fortier calls 'ontological security' (Fortier 2002) of being among kindred spirits, that is often central to the experience of both immigrants and queers. What's more, in the case of queer immigrants, the ethnic and the sexual connectivity are interwoven. 'Being among kindred' and 'being understood', frequently mentioned in e-mail interviews, refers not only to sexuality but also to the language, Russian past and shared experience of immigration to Israel. But we should also remember that such a feeling of security is mediated by the very nature of interactions on-line, which are based on complicated games of anonymity and intimacy, privacy and disclosure. In the case of closeted gays and lesbians, for example, cyberspace can provide an opportunity to meet the like-minded and perform one's sexuality (albeit virtually), while remaining anonymous. Further, we can ask about possible forms of anonymous

\footnotetext{
${ }^{8}$ On the notion of performativity and belonging, see, for example, the special volume of Theory, Culture and Society (Bell 1999).
} 
intimacy that can sometimes characterize both queer and cyber spaces. To return to the notion of feeling at home on-line, I would like to mention multiple metaphors of belonging that I came across during my participation in the website's daily life. The website and its space were compared to family, community, one's home-country or one's town. Again, the variations of those metaphors are and will be discussed beyond this paper. In the context of my current discussion of home, however, I would like to point out that these images of shared collectivity, comfort and connection represent what Avtar Brah (1996) calls 'homing desires'-a desire for a place of belonging which is homey, yet is not necessarily located in ones' homeland.

But what are the relations between homey places, feeling at home and a national homeland, which, as Avtar Brah reminds us, are not the same? For the Russian speaking Jews who have emigrated from the former Soviet Union in the past decade, 'homeland' is not located in one single place. It is multiple and contested. It is about uprooting and regrounding (Ahmed et al 2003), migration and multiple diasporic attachments. It is about the Russia they left behind, the Russian and the Jewish culture they carry, re-imagine and perform. It is also about Israel, which is officially defined, and indeed perceived by many - as their historical homeland. And, although this aspect is usually silenced, this home is also about the displacement, uprooting and oppression of the Palestinian people, on which the Jewishness of the Israeli state is based.

Queer sexuality and identity complicated the question of home and belonging for Russian GLBTs even more. For so many of them their queer identity and their participation in a GLBT community are only possible online: some of the participants live in heteronormative marriages, others reside in closed and often homophobic communities or remote areas, far from clubs and GLBT centers. For others, virtual interactions are yet another arena of community life, where they can discuss a social evening that took place in a club or a party they had been to. And again, online space provides an opportunity to resist the dominant ideas of sexuality and the homophobia of Israeli and Russian-migrant societies.

Online community provides new opportunities for diasporic and migrant subjects. 'Cyborg-Diaspora', using Indira Karamcheti's (1992) and Radhika Gajjala's (2002) words, is a space for creating migrant community through technology that can disrupt dominant discourses of nation, ethnicity and culture. It could also be a space where immigrants can resist the hegemony of language of their host society. For example, the website's name, 'The Pan-Israeli Portal of Russian speaking GLBTs', challenges the Zionist idea of Israeli identity as embedded in Hebrew language, and proposes instead a new kind of identity: a Russian-speaking Israeli. It thus creates a new home - in language and in cyberspace.

But while opening up some borders and boundaries, such as those of sexuality and ethnicity, the Russian queer cyber community reinforces and reassures others-those of class and nation - thus showing that the idea of queer home in cyberspace is fragile and exclusionary. For example, most of the participants are students with higher education. The dominant class identity of the forum is that of the intelligentsia. Correct language is one of the signs of belonging to that intelligentsia. Thus those participants, whose postings contain multiple spelling mistakes, are often treated with arrogance and scorn. 
Similarly, the forum holds an undeclared consensus with relation to Israeli politics and national identity. For example, political debates about Israel, Jews and Palestinians are quite frequent, which is not surprising, given the fact that Israel is involved in a conflict and its military rule and national borders today are more contested than ever. While at first glance there is a plurality of opinions in relation to the Israeli-Palestinian conflict, in fact it is almost impossible to voice a radical critique of the Israeli occupation without being violently silenced and verbally attacked by other participants. For many of the participants this has not been problematic, but a few decided to withdraw from these discussions or even ceased participating in the bulletin board altogether. It seems then that the homey feeling of a welcoming queer migrant space is far from unproblematic: turning the web-space into a place one can feel at home is conditioned by one's particular form of speech or silence.

The very process of challenging some boundaries while reinforcing others is of course not unique to the studied community or to this particular website. At the same time, cyberspace differs from an off-line community because it offers additional opportunities to perform and destabilize national, ethnic, class and sexual identities. For example, one can choose deliberately to use broken Russian in order to resist the notion of 'proper Russianness' through language. Indeed, there are some participants who continuously distort rules of spelling in an exaggerated textual performance of un-educatedness, shifting every now and then to 'high' language. But where is the line between those who simply cannot pass as educated enough and thus become a target for mockery; and those who have the liberty to 'play illiterate'? In the same way, one can subvert the dominant nationalist discourse by performing exaggerated nationalist hatred or, as someone has recently tried to do, by taking up the identity of 'the enemy'. For example, in one of the discussions a new character appeared, named 'the Daughter of Palestine', who presented, in an exaggerated and jocular way, the Palestinian point of view, otherwise delegitimized and absent from the discussions.

But even when the dominant ideas of racism, nationalism and intellectual superiority seem to be subverted by some of the participants, one should ask what is the overall meaning of this 'subversion' in that particular space. Is it indeed a creative space of multi-vocality, or yet another form of 'identity tourism' (Nakamura 2000), which maybe plays with, but doesn't really dismantle, dominant power relations?

\section{Cyberfield as home-work}

The internet often appears as a site of unlimited possibilities and identity games. In the early to mid 1990s, many scholars were fascinated with what they imagined as disembodied and free-floating identities in cyberspace. Later works challenged this post-modern hype of 'be anyone you want to be in cyberspace'. For example, feminist and critical race theorists further challenged the supposed freedom of identity performance on line by demonstrating that cyber-subjects are far from deracinated and degendered (Nakamura 2000, O'Brien and Shapiro forthcoming). Although cyberspace is often imagined as a borderless deterritorialized frontier, many studies have shown that it often becomes a battlefield of national(ist) conflicts and violence (Boym 2001, Mitra 1997).

What's more, cyberspace does not simply reflect existing off-line identities and power relations, but can silence, sublimate or exaggerate them. Miller and Slater (2000), for 
example, showed how many Trinidadians exaggerate their national identities on-line. Similarly, one can look at the frequent exaggerated performance of racism and class supremacy by many participants as their way of claiming integration into Israeli society, that simultaneously welcomes them as 'Jewish repatriates' under the Law of Return and guarantees them full citizenship rights, yet at the same time often stigmatizes them as racially and culturally 'impure' outsiders.

Cyberspace, thus, may provide new opportunities for home-making, but homes and fields in cyberspace should be examined critically. On the one hand, homes and homey spaces on-line may seem de-territorialized and disembodied due to the nature of on-line communication. On the other hand, they may reflect territorial and embodied identities, communities and conflicts. Cyberspace may satisfy one's 'homing desires', but it may, even at the same time become a space of violence, silencing and exclusion. My continuous fieldwork on the Russian-Israeli GLBT forum has challenged my assumption of automatic belonging to the website for anyone who is a Russian-Israeli immigrant and a queer. It has also problematized my initial understanding of my fieldwork as anthropology-at-home. As this paper shows, there are multiple ruptures that tear the conceptual and the empirical links between homey feelings, sexual and ethnic belonging and national homeland.

I would like to return to my earlier discussion of Visweswaran's call to decolonize anthropology by turning it into home-work, and to my own critique of contemporary debates on cyberethnography that seem to overlook feminist and post-colonial contributions to the conceptualization of fieldwork. In that respect I would like to mention two exceptional examples of critical cyberethnographies: Michaela Fay's study of transnational feminist networks on-line and Radhika Gajjala's research of the South-Asian cyborg-diaspora. Fay's discussion of 'fieldwork at home and about home' raises the need for a careful examination of the interplay of movement, privilege and homemaking in cyberspace in order to trace practices of making home in mobility (Fay 2004). Such examination has to risk the failure of representation of categories such as 'woman', 'race' or 'class' as a political necessity of feminist ethnography (Fay 2002).

Gajjala's account of the 'SAWNET refusal' suggests that 'cyberspace provides a very apt site for the production of shifting yet fetishized frozen homes [...] by and for South Asian diasporics' (Gajjala 2002:178). Yet her own locations in and out of these homes brings her to examine 'silences' and 'betrayals' (Visweswaran 1997) as ways in which her ethnographic authority was and could be disrupted. Most importantly, such disruptions and the very question of representation become even more complicated in cyberspace, since it 'blurs various categories such as public/private, audience/author, produced/consumer and text/human subject' (Gajjala 2002: 184).

Following Fay and Gajjala I approach my fieldwork as not simply ethnography of and at home, but as a home-work. The conceptualization of cyberfield as home-work rather than as simply an 'anthropology at home' or a 'fieldwork at the no-place' moves the discussion away from the distinctions between native- and non-native anthropologists, between going away, going home and going on-line; or between discursive and physical fields and on- and off-line spaces. Instead it turns to ruptures and connections, speeches and silences, performances and erasures that constitute one's experience of negotiating belonging on-line. 


\section{References}

Abu-Lughod, L. 1991. Writing against culture. In Recapturing anthropology: working in the present (ed) R. Fox. Santa Fe: School of American Research Press.

Ahmed, S., C. Castaneda, A. Fortier, \& M. Sheller. 2003. Introduction. In Uprootings/regroundings: questions of home and migration (eds) S. Ahmed, C. Castaneda, A.M. Fortier \& M. Sheller, Berg: Oxford and New York.

Bell, V. 1999. Performativity and belonging. Theory, Culture and Society. London: Sage.

Boym, S. 2001. Nostalgia and global culture: from outer space to cyberspace. In The Future of Nostalgia. New York: Basic Books.

Brah, A. 1996. Cartographies of diaspora: contesting identities. London and New York: Routledge.

Central Bureau of Statistics of Israel. 2002. Statistical abstract. Jerusalem: Central Bureau of Statistics of Israel.

Eichhorn, K. 2001. Sites unseen: ethnographic research in a textual community. Qualitative Studies in Education 14 (4): 565-78.

Fay, M. 2002. Ethnographies-how to enter the field if you're not sure where it is. Unpublished manuscript, Institute for Women's Studies, Lancaster University.

Fay, M. 2004. Locating the field. Paper presented at the ASA conference, Durham.

Fernback, J. 1999. There is a there there: notes toward a definition of cybercommunity. In Doing internet research: critical issues and methods for examining the net (ed) S. Jones. London, New Delhi: Sage.

Fortier, A-M. 2002. Queer diasporas. In Handbook of lesbian and gay studies (eds) D. Richardson \& S. Seidman. London: Sage.

Gajjala, R. 1996. Cyborg diaspora and virtual imagined community: studying SAWNET, www.cyberdiva.org/erniestuff/sanov.html.

Gajjala, R. 2002. An interrupted postcolonial/feminist cyberethnography: complicity and resistance in the 'cyberfield'. Feminist Media Studies 2 (2): 177-93.

Hine, C. 2000. Virtual ethnography. London, Thousand Oaks \& New Delhi: Sage.

Karamcheti, I. 1992. The shrinking Himalayas. Diaspora 2 (2): 261-76.

Kendall, L. 1999. Recontextualizing 'cyberspace': methodological considerations for on-line research. In Doing internet research: critical issues and methods for examining the net (ed) S. Jones. Thousand Oaks, London and New Delhi: Sage.

Kuntsman, A. 2003. Double homecoming: sexuality, ethnicity and place in immigration stories of Russian lesbians in Israel. Women Studies International Forum 26 (4): 299-311.

Lavie, S. \& T. Swedenburg. 1996. Between and among the boundaries of culture: bridging text and lived experience in the third timespace. Cultural Studies 10 (1): 15479.

Markham, A.N. 2004. Reconsidering self and other: the methods, politics, and ethics of representation in online ethnography. In Handbook of qualitative research (eds) N.K. Denzin \& Y.S. Lincoln. Thousand Oaks: Sage. 
Miller, D. \& D. Slater. 2000. The internet: an ethnographic approach. Oxford: Berg.

Mitra, A. 1997. Virtual commonality: looking for India on the internet. In Virtual culture (ed) S. Jones. London: Sage.

Nakamura, L. 2000. Race in/for cyberspace: identity tourism and racial passing on the internet. In The cybercultures reader (eds) D. Bell \& B.M. Kennedy. Routledge: London and New York.

O'Brien, J. \& E. Shapiro (forthcoming). 'Do it' on the web: emerging discourses on internet sex. In Web.studies: rewriting media studies for the digital age (ed) D. Gauntlett. London: Arnold Press.

Oguibe, O. 1996. Foresaken geographies: cyberspace and the new world 'other'. 5th International Cyberspace Conference, Madrid, Spain.

Paccagnella, L. 1997. Getting the seats of your pants dirty: Strategies for ethnographic research on virtual communities. http://www.ascusc.org/jemc/vol3/issue1/paccagnella.html

Stone, A.R.S. 2001. Will the real body please stand up?: boundary stories about virtual cultures. In Reading digital culture (ed) D. Trend. Oxford and Massachusets: Blackwell.

Visweswaran, K. 1997. Fictions of feminist ethnography, University of Minnesota Press: Minneapolis, London.

\section{About the author}

Adi Kuntsman is a doctoral candidate in the Department of Sociology, Lancaster University. Her research interests include feminism, queer sexuality, diaspora, migration, nationalism and cybercultures. Her $\mathrm{PhD}$ explores the relations between nationalism and queer spaces, and examines the interplay of national and sexual belongings in and out of cyberspace.

Email: a.kuntsman@lancaster.ac.uk 